\title{
PELATIHAN PERHITUNGAN HARGA POKOK PENJUALAN DALAM MENENTUKAN HARGA JUAL BARANG DAGANG PADA UMKM DI DESA CIMEKAR KABUPATEN BANDUNG
}

\author{
Wenti Frisca Septiani Putri ${ }^{1}$, Henda Hendawati ${ }^{2}$, Yuli Nawangsasi ${ }^{3}$, Dikdik Maulana ${ }^{4}$ \\ Surya Ansori ${ }^{5}$, Iyan Sukiman ${ }^{6}$ \\ 1, 2, 3, 4, 5, 6 Program Studi D3 Akuntansi, Program Vokasi, Universitas Sangga Buana Bandung \\ ${ }^{1}$ korespondensi : wenti.frisca@ usbypkp.ac.id
}

\begin{abstract}
ABSTRAK
Kegiatan Pengabdian Kepada Masyarakat ini dilatarbelaki hasil survey awal pada pelaku usaha UMKM desa Cimekar Kabupaten Bandung, terdapat permasalahan-permasalahan yang diantaranya adalah: (a) Pengetahuan tentang biaya tetap dan biaya variable yang dimiliki pelaku usaha UMKM masih terbatas; (b) Pengetahuan yang dimiliki pelaku usaha UMKM dalam menyusun harga pokok hanya melihat beban yang mengeluarkan kas saja; (c) Perhitungan harga pokok penjualan belum sesuai Standar Akuntansi Keuangan Entitas Mikro, Kecil dan Menengah (EMKM). Tujuan kegiatan ini membahas mengenai agar pelaku usaha memiliki pengetahuan dan pemahaman tentang perhitungan harga pokok produk dan penyusunan laporan harga pokok produksi sesuai ilmu akuntansi biaya agar dihasilkan informasi biaya produksi yang akurat. Pengabdian ini menggunakan pendekatan pelatihan berupa Fokus Grup Diskusi (FGD), sedangkan sasaran pelaksanaan pengabdian ini yaitu pelaku usaha UMKM di desa Cimekar Kabupaten Bandung yang berjumlah 30 orang. Hasil pelaksanaan pengabdian ini adalah sebagai berikut: (1)Telah dilaksanakan penyuluhan mengenai komponen biaya tetap dan biaya variable; (2)Telah dilaksanakan simulasi kasus dari pelaku usaha secara real mengenai cara menggolongkan biaya tetap dan biaya variabel. (3) Telah dilaksanakan simulasi kasus dari pelaku usaha secara real mengenai penentuan harga jual suatu produk.
\end{abstract}

Kata Kunci: Pengabdian Kepada Masyarakat, Harga Pokok, Pelaku Usaha

\begin{abstract}
This Community Service Activity is based on the results of an initial survey of MSME business actors in Cimekar Village, Bandung Regency, there are problems which include: (a) Knowledge of fixed costs and variable costs owned by MSME business actors is still limited; (b) The knowledge possessed by MSME business actors in compiling the basic price only looks at the burden of disbursing cash only; (c) The calculation of the cost of goods sold is not in accordance with the Financial Accounting Standards for Micro, Small and Medium Entities (EMKM). The purpose of this activity is to discuss so that business actors have knowledge and understanding of calculating the cost of products and preparing reports on the cost of production according to cost accounting in order to produce accurate production cost information. This service uses a training approach in the form of Focus Group Discussions (FGD), while the target for this service is MSME business actors in Cimekar village, Bandung Regency, totaling 30 people. The results of the implementation of this service are as follows: (1) Counseling has been carried out regarding the components of fixed costs and variable costs; (2) A real case simulation has been carried out from business actors regarding how to classify fixed costs and variable costs. (3) A real case simulation has been carried out from business actors regarding the determination of the selling price of a product.
\end{abstract}

Keywords: Community Service, Cost of Goods, Business Actor

\section{PENDAHULUAN}

Usaha mikro, kecil, dan menengah (UMKM) saat ini sedang menjadi titik fokus pemerintah Indonesia dalam membangun kembali perekonomian Indonesia yang menurun drastis akibat dari pandemi Covid - 19 yang menerjang di tahun 2020 . Hal ini tampak dari data terkini tentang proporsi biaya yang dialokasikan untuk menangani dampak ekonomi Covid-19 sektor UMKM, yakni sebesar Rp 123,46 triliun. Proporsi biaya yang dianggarkan untuk UMKM tersebut menempati urutan kedua setelah 
perlindungan sosial yang dialokasikan sebesar Rp 203,9 triliun. Bahkan, proporsi biaya untuk dukungan UMKM jauh lebih besar daripada biaya yang dianggarkan di bidang pembiayaan korporasi yang mendapat jatah Rp 53,57 triliun. Dukungan besar pemerintah terhadap sektor UMKM didasarkan pada besarnya pontensi dan kontribusi sektor UMKM bagi perekonomian Indonesia. Keseriusan pemerintah Indonesia dalam memperhatikan sektor UMKM dapat dilihat dari kebijakan-kebijakan yang tertuang dalam program bantuan, produk hukum terkait UMKM, serta pembentukan lembaga untuk menangani UMKM. Sebagai tulang punggung ekonomi nasional, sektor UMKM memberikan kontribusi dalam pertumbuhan ekonomi, penciptaan lapangan kerja dan penyerapan tenaga kerja, pembentuk produk domestik bruto (PDB), serta sumber ekspor nonmigas [1]. UMKM juga memiliki fungsi sosial sebagai penyedia jaring pengaman, terutama bagi masyarakat berpendapatan rendah supaya dapat menjalankan kegiatan ekonomi produktif. Tak hanya pada saat kondisi ekonomi normal dan stabil, UMKM terbukti kuat saat menghadapi krisis ekonomi yang melanda Indonesia pada tahun 1998 dan 2008. Pada dua krisis itu, sebagian besar UMKM relatif tak mengalami masalah serius. Malah, mereka yang berorientasi ekspor dan menggunakan bahan baku dalam negeri dapat meraih keuntungan. Hasilnya, UMKM mampu menjadi katup pengaman perekonomian nasional saat krisis. Kekuatan UMKM tersebut tidak terlepas dari perputaran transaksi yang cepat, menggunakan produksi domestik dan bersentuhan langsung dengan kebutuhan primer masyarakat. Salah satu tantangan utama yang dihadapi oleh pelaku UMKM adalah terkait dengan pengendalian biaya, UMKM harus mampu mengurangi dan mengendalikan biaya, tanpa mengurangi kualitas dan kuantitas produk yang telah ditetapkan [2]. Pengendalian biaya akan lebih efektif bila biaya-biaya diklasifikasikan dan dialokasikan dengan tepat [3].

Berdasarkan hasil survei yang kami laksanakan, pelaku usaha UMKM di dalam menghitung harga pokok di dasarkan pengeluaran kas saja misalnya listrik, air dan gaji pegawai tetapi untuk biaya depresiasi tidak pernah dibebankan, sehingga dapat kami simpulkan bahwa perhitungan harga pokok penjualan yang dilakukan oleh pelaku usaha UMKM belum sesuai dengan pendekatan full cost, varialel cost maupun activity based costing. Oleh karena itu Tim PKM kami akan melaksanakan pengabdian mengenai perhitungan harga dengan pendekatan full costing.

Berdasarkan analisis situasi pada UMKM di desa Cimekar Kabupaten Bandung, terdapat permasalahan-permasalahan yang diantaranya adalah: (a) Pengetahuan tentang biaya tetap dan biaya variable yang dimiliki pelaku usaha UMKM masih terbatas; (b) Pengetahuan yang dimiliki pelaku usaha UMKM dalam menyusun harga pokok hanya melihat beban yang mengeluarkan kas saja; (c) Perhitungan harga pokok penjualan belum sesuai Standar Akuntansi Keuangan Entitas Mikro, Kecil dan Menengah (EMKM). 


\section{METODE}

\section{Waktu dan Tempat Pelaksanaan}

Kegiatan dilaksanakan selama 3 kali, yaitu pada tanggal 4 November 2020 dan 8 April 2021 dilakukan secara tatap muka bertempat di Kantor Kepala Desa Cimekar, Jl. Sukahaji No. 50 Kecamatan Cileunyi Kabupaten Bandung Kodepos 40623 dan 26 Maret 2021 dilakukan secara tatap maya melalui aplikasi Zoom Meeting.

\section{Pendekatan}

Pendekatan yang kami lakukan untuk memecahkan masalah yang terkait dengan perhitungan harga pokok adalah:

a. Ceramah dan tanya jawab, untuk menjelaskan komponen harga pokok kepada pelaku usaha.

b. Demonstrasi untuk menjelaskan suatu penciptaan model perhitungan harga pokok dengan pendekatan full cost. Dengan demikian peserta dapat mengamati secara langsung penyusunan harga pokok yang berbasis excel.

c. Latihan atau praktik, peserta akan mempraktekkan semua materi yang sudah dijelaskan oleh Tim PKM. Latihan meliputi: mengidentifikasi biaya tetap dan biaya variable, kemudian mencatat ke dalam catatan selebaran yang sudah disediakan oleh Tim PKM. Berdasarkan data yang sudah dimasukkan ke dalam selebaran tadi, kemudian disusunlah harga pokok dengan urutan berdasarkan Prinsip Akuntansi Berterima Umum (PABU) [4].

\section{Sasaran Pengabdian}

Sasaran pengabdian yaitu pelaku usaha UMKM di desa Cimekar Kabupaten Bandung yang berjumlah 30 orang.

\section{Kriteria Keberhasilan}

Indikator keberhasilan dari kegiatan pengabdian ini adalah karyawan mampu mengidentifikasi biaya variabel dan biaya tetap serta mampu menghitung harga pokok dengan mengggunakan pendekatan full cost baik secara manual maupun dengan menggunakan perangkat pembantu microsoft excel.

\section{HASIL DAN PEMBAHASAN}

Berdasarkan analisis situasi yang dihasilkan dari kegiatan survey awal di desa Cimekar Kabupaten Bandung yang menyebutkan bahwa pelaku usaha UMKM dalam menyusun harga pokok hanya melihat beban yang mengeluarkan kas saja, belum dituangkannya prosedur dalam bentuk klasifikasi yang baik, pemahaman yang masih kurang mengenai pencatatan sesuai dengan Prinsip Akuntansi Berterima Umum (PABU). Pendekatan yang dilaksanakan dalam pengabdian berupa pelatihan berbentuk Fokus Grup Diskusi (FGD), pada hari pertama pelatihan dipaparkan secara sekilas mengenai penentuan harga pokok, dengan mengumpulkan data-data pelaku usaha dengan bidang usaha yang di ampu nya, karena setiap bidang usaha akan berbeda perlakuan dalam perhitungan harga pokok nya, maksud dari mengumpulkan data tersebut agar di pertemuan berikut nya bisa dipecah berdasarkan kelompok dengan karakteristik bidang usaha yang serupa. 
P-ISSN: 2745-5912

E-ISSN: 2745-9047

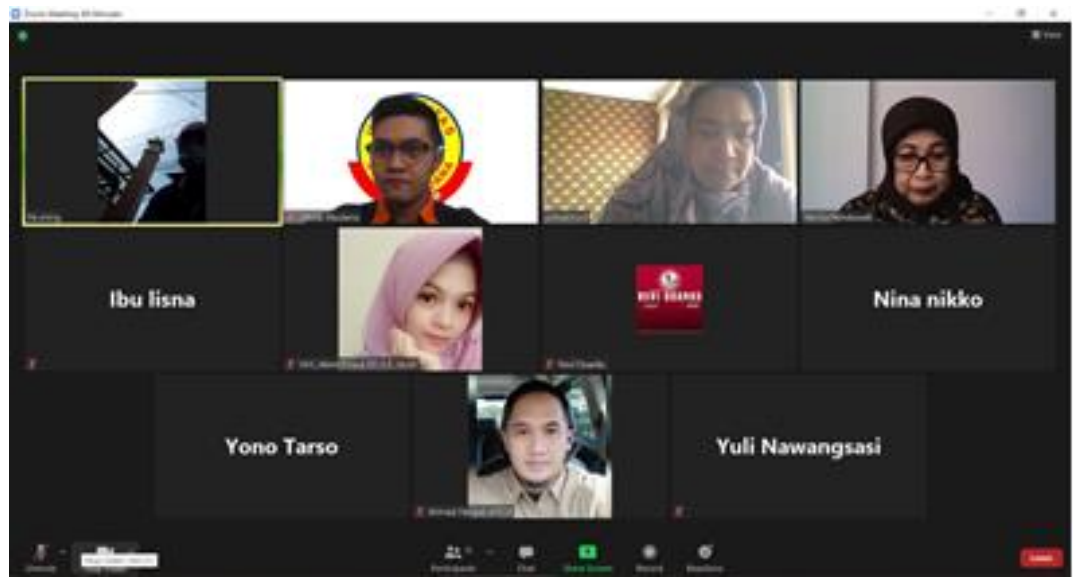

Gambar 1: Tim PKM melakukan tatap maya dengan pelaku usaha desa Cimekar

Pada pertemuan kedua diberikan penjelasan dilakukan secara tatap maya melalui aplikasi Zoom Meeting, Tim PKM memberikan penyuluhan mengenai perhitungan harga pokok dengan pendekatan full cost, dengan tujuan perhitungan ini relatif lebih mudah sehingga pelaku usaha tidak kesulitan untuk mempraktikan dalam usahanya. Adapun materi penyuluhan yang dilakukan oleh Tim PKM meliputi:
1. Menjelaskan komponen biaya tetap dan biaya variabel

2. Mengidentifikasi biaya-biaya yang mana disetiap kelompok pelaku usaha akan di simulasikan

3. Menggolongkan rincian biaya tetap dan rincian biaya variabel berdasarkan biaya bahan baku, tenaga kerja, biaya overhead pabrik, biaya pemasaran dan biaya administrasi dan umum dan yang terakhir komponen biaya overhead variabel.

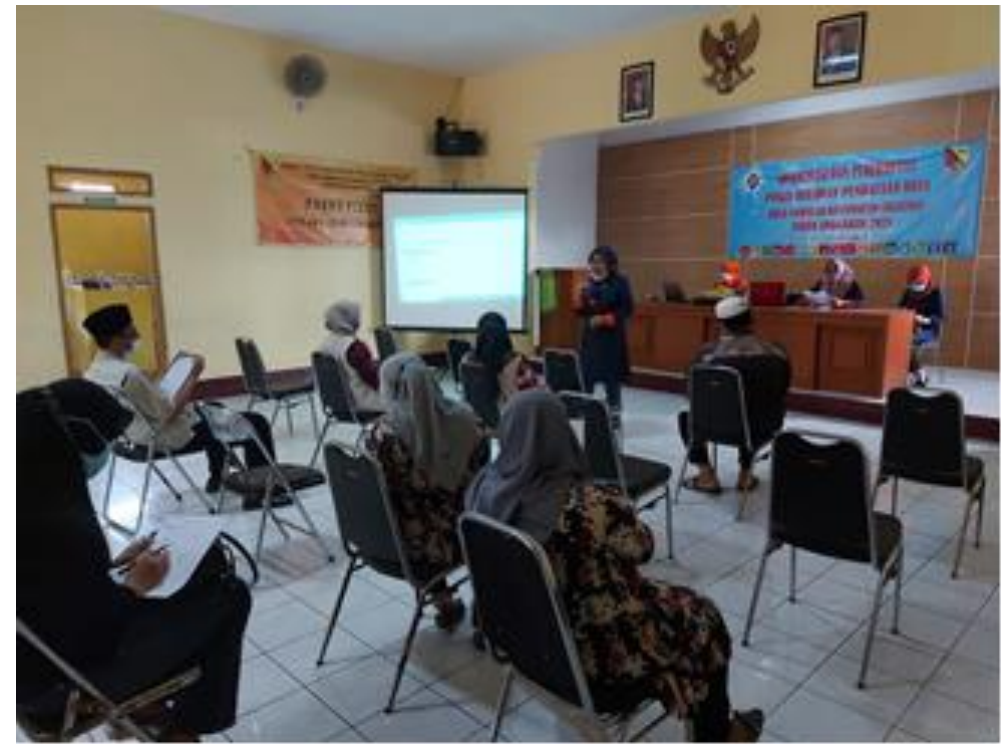

Gambar 2: Tim PKM sedang melakukan pemaparan penentuan harga pokok

Pada pertemuan ketiga dilakukan simulasi kasus secara real berdasarkan kelompok yang sebelumnya telah di bagi berdasarkan karakteristik usaha yang sama, tim pengabdian 
telah membuat format perhitungan harga pokok produksi yang sesuai dengan ilmu akuntansi biaya-biaya dengan menggunakan manual. Tim pengabdian telah melakukan penyampaian materi tentang metode/pendekatan harga pokok produksi. Tujuan disampaikannya meteri ini adalah agar pelaku usaha memiliki pengetahuan dan pemahaman tentang perhitungan harga pokok produk dan penyusunan laporan harga pokok produksi sesuai ilmu akuntansi biaya agar dihasilkan informasi biaya produksi yang akurat.

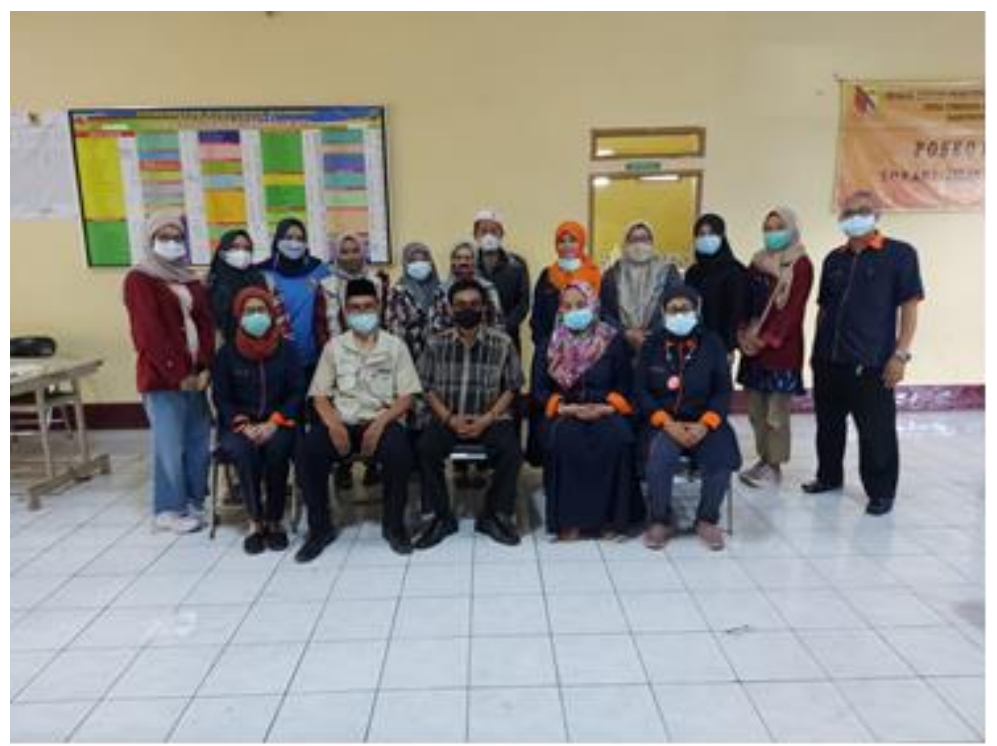

Gambar 3: Tim PKM USB YPKP, Pelaku Usaha beserta Perangkat Desa

\section{Kendala dan Pemecahannya}

Pelaksanaan pengabdian kepada masyarakat dengan tema Pelatihan Perhitungan Harga Pokok Penjualan Dalam Menentukan Harga Jual Barang Dagang Pada UMKM Di Desa Cimekar Kabupaten Bandung telah terlaksana dengan baik. Meskipun demikian, pada pelaksanaan tersebut bukan berarti tidak menemui berbagai hambatan. Salah satu hambatan yang ditemui pada kegiatan penyuluhan adalah terbatasnya alat pembantu seperti laptop/pc yang hanya dimiliki oleh beberapa pelaku usaha dalam perhitungan harga pokok penjualan dan penentuan harga jual produk, selain itu pelaku usaha masih merasa kurang percaya diri dalam mengerjakan dan menyelesaikan kasus latihan yang di berikan oleh tim PKM. Untuk mengatasi permasalahan tersebut, dilakukan pendampingan secara terusmenerus dan dilaksanakan semaksimal mungkin.

\section{PENUTUP}

Berdasarkan kegiatan pengabdian yang telah dilaksanakan dapat disimpulkan pengabdian berupa pelatihan berbentuk Fokus Grup Diskusi (FGD) telah terlaksana sesuai dengan jadwal dan kriteria keberhasilan dengan hasil pelaksanaan pengabdian ini adalah sebagai berikut:

1. Telah dilaksanakan penyuluhan mengenai komponen biaya tetap dan biaya variabel.

2. Telah dilaksanakan simulasi kasus dari pelaku usaha secara real mengenai cara 
menggolongkan biaya tetap dan biaya variabel.

3. Telah dilaksanakan simulasi kasus dari pelaku usaha secara real mengenai penentuan harga jual suatu produk.

Pelatihan perhitungan harga pokok diharapkan dapat diterapkan secara permanen di Pelaku usaha UMKM guna pengambilan keputusan penetapan harga jual dan digunakan untuk mengestimasi laba yang diperoleh UMKM. Selain itu hendaknya dilaksanakan kegiatan lanjutan sebagai tindak lanjut atas kegiatan pengabdian yang telah dilaksanakan, berupa pendampingan pelaksanaan penelitian.

\section{DAFTAR PUSTAKA}

[1] Kompaspedia.kompas.com (2020). Perkembangan Kebijakan Pemerintah terhadap UMKM di Indonesia dari https://kompaspedia.kompas.id/baca/pa paran-topik/perkembangan-kebijakanpemerintah-terhadap-umkm-diindonesia

[2] Kompaspedia.kompas.com (2020). Potret dan Tantangan UMKM di Indonesia dari https://kompaspedia.kompas.id/baca/pa paran-topik/potret-dan-tantanganumkm-di-indonesia

[3] Sujarweni, V. W. (2017). Implementasi Penentuan Harga Pokok Produksi Untuk Mencapai Laba Optimal (Studi Pada Sentra Ukm Industri Bakpia Di Wilayah Minomartani Sleman Yogyakarta).

[4] Animah, Adhitya, \& Widia (2021). Pelatihan Perhitungan Harga Pokok Berbasis Excel pada Hotel Rumah Putih Abu-Abu. Jurnal Selaparang Pengabdian Masyarakat Berkemajuan, Volume 4, Nomor 2, April 2021 Diambil dari 